\title{
Towards a brain-to-society systems model of individual choice
}

Laurette Dubé • Antoine Bechara • Ulf Böckenholt •

Asim Ansari • Alain Dagher • Mark Daniel •

Wayne S. DeSarbo • Lesley K. Fellows •

Ross A. Hammond • Terry T.-K. Huang •

Scott Huettel • Yan Kestens • Bärbel Knäuper •

Peter Kooreman • Douglas Spencer Moore •

Ale Smidts

Published online: 7 November 2008

(C) Springer Science + Business Media, LLC 2008

Erratum to: Market Lett (2008) 19:323-336

DOI 10.1007/s11002-008-9057-y

The original version of this article unfortunately contained mistakes. First, the affiliation of Dr. Ale Smidts was incorrect. The corrected affiliation is stated below.

Second, there's a typographical error in the publication of Klurachev et al. (2008) in the Reference list.

The corrected reference is:

Klucharev, V., Hytonen, K., Rijpkema, M., Smidts, A., and Fernandez, G. (2008). An error of being different? Brain mechanisms of social norms. Working Paper, F. C. Donders Center for Cognitive Neuroimaging, Radbout University Nijmegen.

The online version of the original article can be found at http://dx.doi.org/10.1007/s11002-008-9057-y

L. Dubé $(\bowtie) \cdot$ U. Böckenholt

Desautels Faculty of Management, McGill University,

1001 Sherbrooke St. West, Montreal, Quebec, Canada H3A 1G5

e-mail: laurette.dube@mcgill.ca 


\section{A. Bechara}

Brain and Creativity Institute, University of Southern California, Los Angeles, CA, USA

\section{A. Ansari}

Columbia Business School, New York, NY, USA

\section{A. Dagher}

The Montreal Neurological Institute, McGill University, Montreal, Canada

M. Daniel

CHUM- Centre de Recherche, Axe santé des populations, Montreal, Quebec, Canada

W. S. DeSarbo

Smeal College of Business at the Pennsylvania State University, University Park, PA, USA

L. K. Fellows

Neurology and Neurosurgery, Montreal Neurological Institute and Hospital, Montreal, Quebec, Canada

R. A. Hammond

Economic Studies Program, The Brookings Institution, Washington, DC, USA

T. T.-K. Huang

National Institute of Child Health \& Human Development, Bethesda, MD, USA

S. Huettel

Department of Psychiatry and Behavioral Sciences, Duke University, Durham, NC, USA

Y. Kestens

Dép. Médicine Sociale and Préventive, Université de Montréal, Montreal, Quebec, Canada

B. Knäuper

Department of Psychology, McGill University, Montreal, Canada

P. Kooreman

Department of Economics, Tilburg University, Tilburg, The Netherlands

D. S. Moore

School of Kinesiology and Health Studies, Queen's University, Kingston, ON, Canada

A. Smidts

Rotterdam School of Management, Erasmus University Rotterdam, Rotterdam, The Netherlands 